\title{
TO USAGE OF NAMES WITH A DIFFERENT STRUCTURE
}

\author{
Levan Khalvashi ${ }^{1}$, Lia Gorgadze ${ }^{2}$ \\ ${ }^{1}$ Dr., Faculty of Humanities, Batumi Shota Rustaveli State University, Georgia, \\ levan.khalvashi@bsu.edu.ge \\ ${ }^{2}$ Ms., Faculty of Humanities, Batumi Shota Rustaveli State University, Georgia, \\ Lia.gorgadze@bau.edu.ge
}

\begin{abstract}
The definition of the noun was formulated by Dionysius, the author of the first European grammar, and it is represented by slight differences in words in the descriptions of different languages. In the article, the author draws attention to the observed discrepancy between the use of a noun in speech and the definition of a part of this speech, established in linguistic theory. The Dionysian definition gives the noun only one meaning, the subject, and in Georgian, English, Russian, Turkish, and other languages, in addition to expressing the subject, the noun also has predicative, attributive, and adverbial functions. Based on the foregoing, the article correctly formulates the problem of defining a noun established in grammar. However, the suspicions expressed during the study need to be confirmed. By diachronic discussion of linguistic theory and analysis of extensive illustrative material, the author manages to create the necessary base of approval. The purpose of the author's research in the presented work is to analyze where under what influence the traditional definition of a noun was formed. However, the position of the author of the article is interesting, according to which the definition of a name established in grammatical sources is inaccurate from a scientific point of view. The research begins by clarifying the background of the issue. The essential features of speech in logistic grammars are discussed interestingly. The actuality of the paper-The noun is part of the main universal speech, without the use of which neither speech nor thinking is possible. The author of a linguistic, philosophical, and other scientific text must consciously or unconsciously express his understanding of the relationship between an object, an idea, and a name. This relationship defines the scientific paradigm in linguistics and philosophy. The definition of a noun established in the linguistic tradition was formed when language began to be understood in scientific thought as a passive form of expressing thought, which determined the logistic methodology of its study. In our time, thanks to W. Humboldt, L. Wittgenstein, J. Austin, a new understanding of language as a form of thought and a form of the world has been formed, but the definition of a noun remains old - ancient. The purpose of our study is to identify the factors that led first to the formation of the traditional definition of the noun and then to its approval in linguistic theory. As a result of observations, in-depth analysis, and assessment, the document indicates the source of the inaccuracy, which was previously not paid attention to in linguistic theory.
\end{abstract}

Keywords: noun, languages, ancient philosophers, grammar

\section{THE ACTUALITY OF THE PAPER}

The noun is part of the main universal speech, without the use of which neither speech nor thinking is 
possible. The author of a linguistic, philosophical, and other scientific text must consciously or unconsciously express his understanding of the relationship between an object, an idea, and a name. This relationship defines the scientific paradigm in linguistics and philosophy. The definition of a noun established in the linguistic tradition was formed when language began to be understood in scientific thought as a passive form of expressing thought, which determined the logistic methodology of its study. In our time, thanks to W. Humboldt, L. Wittgenstein, J. Austin, a new understanding of language as a form of thought and a form of the world has been formed, but the definition of a noun remains old - ancient. The purpose of our study is to identify the factors that led first to the formation of the traditional definition of the noun and then to its approval in linguistic theory.

To achieve this goal, it is necessary to solve the following tasks:

1. Creation of a theoretical basis for research

2. Critical analysis of the existing theory.

Research methodology Collection and classification of empirical material, contrast, and diachronic analysis.

\section{Metaphysical foundations of grammar}

We are discussing the problem of the name in the philosophy of Plato and Aristotle. Our interest in these two ancient philosophers is linguistic in nature: modern grammars have a metaphysical basis. It is true that Plato and Aristotle did not create scientific linguistic works, but their thought laid the foundation for scientific methodology and, thus, determined the principles for the creation of the first European grammars.

Ancient grammar arose outside the linguistic scientific paradigms, when there was no scientific theory reflecting the general nature of language, there was no metalanguage of linguistics.

It is known that specialists connected the formation of linguistic thought as a science with the introduction of the historical-comparative method into the practice of language research at the beginning of the 19th century, while the earlier period was called "pre-scientific".

In the work "General Linguistics" Arn. Chikobava distinguishes between two terms: "linguistics" and "thinking about language." The second he also refers to the ancient grammars.

Ancient grammars are unscientific because their authors could not distinguish between language and speech and therefore misinterpreted the relationship between word and object, word and concept, sentence and thought. This was caused not so much by the individual methodological error of the ancient grammarians (Dionysus, Donatus, Priscian, Varro, Apollonius, etc.), but by the general worldview philosophical factor. The question is, how could philosophy determine the nature of a work of grammar? We must take into account the fact that both philosophical teaching and grammatical description are theories. And the relationship between theories is hierarchical. T. According to Kuhn, the relationship of theories is determined by the academic degree of each. T. Kuhn identifies a "paradigmatic" (revolutionary) theory, which is an example of generally accepted knowledge. ("Disciplinary Matrix") that allows the scientific community to solve a problem (Kuhn, 1977:11;28). The theory of the philosophical paradigm determines the consciousness of many people, because it forms the basic concepts of thinking and, therefore, people's attitudes to the world, in particular, the vision and value of things. We can also recall the words of Friedrich Nietzsche: "Philosophy always creates the world" (Nietzsche, 1977:66). The author of a scientific theory cannot avoid philosophy.

The universe, "existing" in ancient terminology, includes three areas: physical, mental, and linguistic. In scientific theory, the author expresses with others his knowledge about the structure of the existing, namely, how he understands the relationship of the world, thought, and language. This is the universal foundation of scientific theory. The relationship of the word, subject, and idea, given in ancient grammars, was originally philosophical, it was formulated in the metaphysics of Plato and Aristotle. It is well known that the principles of ancient grammar subsequently formed many national grammars. Thus, we have reason to speak about the metaphysical basis of grammars.

The relationship to Plato between words, objects, and ideas is due to the metaphysical meaning of the universe. According to Plato, in the physical world, "everything flows back and forth like European waves, and does not stop for a moment in the same state," so that "there is no truth in things or words, and nothing in it." (Plato,1966:47). Plato paradoxically expresses this truth in "Thimeos": the universe is "that which is born forever and never exists." (Plato, 1994:288). Philosophical searches of Plato have one direction: from physical chaos to the eternal, heavenly order. Plato refers to the ideal beings of things - ideas (idos). The 
first abode of ideas is the eternal sky. According to Plato, the eternal sky begins in the immortal soul of a person, therefore, a person can explore the eternal world through the contemplation of ideas in the soul. Ideas like this give rise to an infinite number of objects. Thus, the relationship with Plato is hierarchical between ideas, objects, and words. Plato attributes absolute value to ideas that give rise to objects. In Plato's hierarchy, the lower ranks are occupied by names - empty physical forms that simply express eternal ideas and denote physical objects. An eternal essence (idea) cannot be an integral part of a physical word, therefore a name cannot be associated with an object through an essence. Plato's names are devoid of content. In this regard, it is interesting to consider the figurative definition of Plato's language in Timaeus: "The source of words spoken from the mouth, serving the meaning, is the most beautiful and best of the fountains. " (Plato,1994:340) "A fountain is a stream of water pouring from the surface, so, like it, a language in an articulated space outside a person can be just a form of sound. A language that is not of this kind cannot be a participant in the mind of thought. It only expresses thoughts., which are not an integral part of it, and therefore the connection between language and thoughts is not fundamental, it is only necessary for terms of expression. (Khalvashi, 2014:20). Thus, Plato's language is simply the expression of objects and ideas.

Aristotle spent twenty years at Plato's academy, so it is not surprising that Aristotle, like Plato, the physical world is impossible without ideas. In "Metaphysics" Aristotle writes: "If there is nothing but single objects, and the number of subjects is infinite, then how can we achieve knowledge of infinite objects?" We know all subjects so well that they have something in common ... "(Aristotle, 1976:109) But Aristotle admitted eternal ideas (beginnings) only in the mind, therefore it was important for him to understand the nature of constantly changing objects. Every object is composed of matter and form. The subject is permeable: it arises and disappears, while the form remains because it (the form) has the face of another, an eternal idea placed in the mind. In addition to the eternal "form-ideas", in the "organon" Aristotle also speaks of emerging ideas (forms and persons), concepts in modern terminology. Concepts arise through the representation of physical objects (substances) as a result of reflection and generalization (induction) in consciousness. Thus, for Aristotle, ideas are the ontological and epistemological basis of the universe, but, unlike Plato, Aristotle's ideas do not form the physical world. What exists in Aristotle, as in Plato, has only two faces: the ideal and the physical. Both philosophers did not admit the linguistic world. Like Aristotle, Plato, language expresses only objects and ideas and cannot create the universe. Such a language cannot have its own content, therefore in metaphysics, we find a strange definition of grammar as a science by one assessment. "What is one of the sciences-grammar, it studies all the sounds of speech" (Aristotle,1976:120). This illustrates well how the founders of metaphysics understood language.

\section{Conclusion}

The ancient definition of the noun was based on the philosophical worldview and epistemological principles that prevailed during this period: the physical world (substance, property, quantity, relation, time, place, belonging, action, state, passion) is objectively ("reflected")) is reflected in human consciousness and then transmitted through the language. Parts of speech express categories of thought and mark the corresponding referents (essence, property, action, place, time ...). The Dionysian definition of "a name is part of a rotating expression denoting a body or object, such as a stone, upbringing" may have originated in this paradigm of scientific thought.

The definition of a noun given in the first European grammar is not the result of observation of the use of ancient Greek or any other language. In ancient Greek, as in all other languages, in addition to the subject meaning, the noun is usually used with attributive, adverbial, and predicate meanings. This fact could not be properly appreciated using logistic grammar.

In the absence of a syntactic theory, Dionysus could not substantiate the meaning of a noun with a syntactic function. The Alexandrian grammar used Aristotle's discovery of a noun to determine the root of a noun: a physical object ("subordinate") in thinking (reasoning) is always a noun, but Aristotle speaks of a logical noun (subject), not a grammatical noun. (noun). The definition of a noun given in the Techne Grammar is a misinterpretation of Aristotle's principle.

In the 17th century, A. Arno and Lancelot equated the structure of the sentence with the structure of thought and thus declared the parts of thought (subject-predicate) as members of the sentence, justified logicism in grammar, and thus facilitated the establishment of the Dionysian version of the noun in grammar. Henceforth, the subject of a noun was proved by the ability of a part of this speech to act in the syntactic role of a subject (subordinate). A circle was formed: first, the word denoting the subject (subordinate) was mistakenly identified with the noun, and then the subject of the noun was confirmed by the connection of a part of this speech with the subject. 
Along with expression, language shapes thinking. The theory of logistic grammar avoids considering examples when one-word acts as different parts of speech, which is logically impossible. Each language is a system that classifies the world in its way, which forces one to study its structure, in contrast to other linguistic structures, when describing one language. The first European grammars, if they did not take into account the data of other languages, could not scientifically reflect the structure of the Greek language itself, because at best they described speech, not language. However, the theory of parts of speech began with a contradiction between a noun and a verb in logic, not grammar. Philosophers distinguished from each other not the corresponding words, but the parts of thought - the subject and the predicate. The first was called "name" and the second was called "verb." The use of these terms in grammar has also helped to blur the line between logical and grammatical in a sentence.

In grammatical theory, the existing division of syntactic functions (noun-subjunctive-adjective, verb-predicate, adjective-attribute, adverb) is not entirely linguistic, since the chapter is based not on the analysis of words, but the reference of the physical object with the parts of thoughts.

Aristotle's observation that, as a predicate, a noun no longer denotes a subject, but only defines it, implies that a name cannot be complete in the function of a predicate, because it loses its subjectivity. If we reduce the meaning of a noun only to the subject, then its syntactic functions should also be limited to additional additions. But only a logical name (subject) has a substantive meaning, and not a grammatical (noun), which has always been used in all languages in the role of a predicate because without it, it becomes impossible to use the language about the World.

A noun is a part of speech that, together with the subject, has always expressed attribute and adverbial meanings from the very beginning, but the logistic postulate does not allow to see this obvious fact: the name refers only to the subject.

In addition to the noun expressing the predicate, attribute, adverb, the corresponding parts of speech (verb, adjective, adverb) have been formed in languages, but languages do not have only a part of speech expressing the subject.

A noun is a part of multifunctional speech used in a sentence with the functions of a predicate, subjunctive mood, addition, attribute, adverb. All syntactic functions are important for a noun.

\section{REFERENCE LIST}

Aristotle, 1976, Book 4, Misl, M.

Plato, 1966, Phaedo, Nakaduli, Tbilisi.

Plato, 1994, Timaeus, "Irmisa", Tbilisi.

Khalvashi L, 2014- General Linguistics, Universal, Tbilisi. 